\title{
Fraternidade como Alternativa à Seletividade do Direito Penal
}

\author{
Fraternity as an Alternative to the Selectivity on Criminal Law
}

\author{
Sérgio Ricardo Aquino Fernandes
}

Faculdade Meridional, Passo Fundo - RS, Brasil

Mayara Pellenz

Faculdade Meridional, Passo Fundo - RS, Brasil

\section{Ana Cristina Bacega de Bastiani}

Faculdade Meridional, Passo Fundo - RS, Brasil

\begin{abstract}
Resumo: Este artigo reflete sobre a necessidade do Direito Penal aproximar-se da Fraternidade como um passo importante na superação da crise vivenciada no tocante à seletividade do Direito Penal brasileiro. O objetivo da pesquisa refere-se, assim, a correlacionar Fraternidade e Seletividade do Direito Penal, buscando alternativas para a superação das crises sociais que assolam o Estado e a Sociedade. O método utilizado, para tanto, refere-se ao indutivo. Entende-se, a partir da investigação, que a Fraternidade é um valor a ser revisitado constitucionalmente e (re)experimentado cotidianamente, propiciando espaço às experiências genuinamente humanas, especialmente quando se trata da crise enfrentada na esfera penal, necessariamente segregadora.
\end{abstract}

Palavras-chave: Fraternidade. Direito Penal. Seletividade.
Abstract: This paper reflects the need of an approach of Criminal Law and Brotherhood as an important step in overcoming the crisis experienced regarding the selectivity in Brazil. The main objective is to correlate Brotherhood and selectivity of Criminal Law, seeking alternatives to overcome the social crisis plaguing state and society. The method to guide this study is the inductive. It is understood from the research that Brotherhood is a value to be revisited by Constitucional law and (re) experienced daily, providing space to human experiences, especially when it comes to the crisis facing the criminal sphere and it's discriminate nature.

Keywords: Brotherhood. Criminal Law. Selectivity.

Recebido em: 18/05/2016

Revisado em: 10/03/2017

Aprovado em: 20/05/2017 


\section{Introdução}

Pretende-se com o presente trabalho discorrer, ainda que brevemente, sobre a Fraternidade como qualidade política, enfatizando sua dimensão ética e humanística. A Fraternidade é um princípio presente no preâmbulo constitucional e por esse motivo está ligada aos objetivos a serem perseguidos pela República Federativa do Brasil.

Além desses argumentos, verifica-se como a Fraternidade é um dos pilares do Estado Democrático de Direito quando orienta todo ordenamento jurídico e integra a terceira geração de Direitos Fundamentais. Essa categoria será abordada nesta pesquisa como valor a ser resgatado para se enfrentar as crises - sociais, jurídicas e políticas - vivenciadas pela sociedade brasileira, especialmente acerca da Seletividade do Sistema Penal.

A Fraternidade, por muito tempo restou, esquecida, encoberta por valores que pareciam mais essenciais, úteis e imediatos. No entanto, com todas as transformações sociais que se manifesta(ra)m no decorrer do tempo, a Fraternidade deve ser incorporada pelo Direito para suscitar atitudes fraternas e de responsabilidades perante o Outro. O Direito ${ }^{1}$, como um fenômeno que acompanha as transformações da Sociedade $^{2}$, deve estar atento a esse processo.

Existe uma crescente conscientização a respeito da importância da Fraternidade para o mundo da vida. No entanto, ainda se carece dessa mesma consciência a respeito da importância dessa categoria no mundo jurídico, em especial na esfera penal. Diante desse cenário, este estudo

\footnotetext{
${ }^{1} \mathrm{O}$ Direito pressupõe certa estabilidade de valores e conceitos para que a norma escolha os conteúdos normativos e torne-se exigível. É fenômeno que surge em razão da sociedade e lei que se direciona a esta mesma sociedade quando a partir da norma direciona a realização ou abstenção de determinada conduta (BITTAR, 2009).

2 "A sociedade, enquanto fenômeno humano, decorre da associação de homens, da vida em comum, fundada na mesma origem, nos mesmos usos, costumes, valores, cultura e historia. Constitui-se sociedade no e pelo fluxo das necessidades e potencialidades da vida humana; o que implica tanto a experiência da solidariedade, do cuidado, quanto da oposição, da conflitividade. Organização e caos são pólos complementares de um mesmo movimento - dialético - que dá dinamismo à vida da sociedade". (DIAS, 2010, p. 487).
} 
contribui para a construção da Fraternidade como uma categoria jurídica, para que esta seja inserida na produção, interpretação e aplicação do Direito a fim de favorecer e assegurar relações humanas as quais não se identifica o Outro como "inimigo" no qual o tratamento para sua "aceitação social" seja pela via da punição.

Este estudo é pertinente diante da atual dinâmica social do país, no tocante à Seletividade do Direito Penal, resultado de uma construção sociocultural bastante diversificada. Observa-se uma influência da linguagem, da cultura, da mídia e da imposição de valores sociais nos discursos de poder, que estão, a todo tempo, legitimando um processo de eleição - ainda que inconsciente - de condutas criminosas e do perfil do criminoso. Os processos de criminalização são objetos de estudo da Criminologia Crítica, que busca respostas aos questionamentos oriundos da relação existente entre criminalidade e capitalismo.

Nesse sentido, a própria Ciência Penal é colocada à prova e proporciona o problema a ser resolvido por essa pesquisa, ou seja, qual é a função que o Direito Penal deve, hoje, cumprir, conforme a sua autêntica utilidade diante das relações humanas? Com hipótese, entende-se que o direito penal deve ser um mecanismo de punição aos infratores, mas de maneira uniforme, modificando as concepções humanas de eleição de estereótipos dos potenciais infratores. Essa situação ocorre, pois ainda hoje forças sociais desvelam perfis mais vulneráveis, ou ainda, perfis responsáveis pela violência desmedida que aterroriza a Sociedade. Os grupos privilegiados, ou ainda, as forças sociais mais expressivas determinam os destinatários da norma penal. Legitimam-se processos históricos de dominação e se agravam as segregações sociais já existentes, o que denota um caráter de preconceitos humanos em relação às características físicas e sociais de determinadas pessoas.

A repressão institucional é sustentada pelo sentimento de raiva, medo ou vingança de quem domina, ao passo que a punição é direcionada àquele que já é vitimado pela exclusão social. Os impulsos sociais vão ao encontro de uma violência que seleciona e controla, aliada à um Sistema Penal que se mostra instrumento de opressão e dominação por excelência. 
A institucionalização do controle e a legitimação dos discursos de poder demonstram a falta de sintonia entre o Direito Penal e suas funções. Os rígidos critérios para a intervenção penal estão relativizados, pois se direcionam a perfis predeterminados. As consequências desse processo são gravíssimas: as cotas de violência inseridas nas relações sociais estão em crescimento, assim como a população carcerária. Além desses argumentos, essa dinâmica sustenta o discurso da relativização de Direitos Humanos, em nome da manutenção da "ordem pública" e da preservação de uma lógica institucional que a própria sociedade corrobora. O Estado de Direito encontra-se esfacelado, diante dos componentes arbitrários que restringem a liberdade e enfraquecem os direitos. Evidente que uma neutralização de interesses não é um objetivo a ser perseguido.

O exercício do poder punitivo legitima o controle social e as ilegalidades cometidas, e, ao mesmo tempo, os discursos sociais, jurídicos e midiáticos sustentam o "poder de punir". A situação crítica é observada em todo o país e em razão dessa situação é que se apresenta o objetivo da pesquisa que se refere a: correlacionar Fraternidade e Seletividade do Direito Penal buscando alternativas para superação das crises sociais que assolam o Estado e a Sociedade, já que o Direito mostra-se falido em vários aspectos. Como objetivos específicos encontram-se: demonstrar a importância do resgate da fraternidade como um princípio a reger as relações humanas; delimitar a fraternidade como uma categoria jurídica exigível; demonstrar que o Direito pode ser o meio de potencializar a fraternidade como um princípio a orientar as relações humanas; delimitar a seletividade do direito penal; e perceber se a seletividade do direito penal pode sofrer uma influência e transformar-se a partir do ideal de Fraternidade.

Para cumprir essa finalidade, a pesquisa desenvolve-se por meio do Método Indutivo ${ }^{3}$, cuja premissa menor é a existência da categoria Fraternidade como critério de organização social e seu desvelo para modificar o cenário de Seletividade do Sistema Penal - caracterizada como a premis-

\footnotetext{
3 "[...] base lógica da dinâmica da Pesquisa Científica que consiste em pesquisar e identificar as partes de um fenômeno e colecioná-las de modo a ter uma percepção ou conclusão geral.” (PASOLD, 2011, p. 205).
} 
sa maior. As Técnicas utilizadas são a Pesquisa Bibliográfica ${ }^{4}$, a Categoria $^{5}$ e o Conceito Operacional ${ }^{6}$.

\section{A Fraternidade como um Princípio a Ser Resgatado}

Historicamente, observa-se que o Homem conquistou seus direitos por meio de lutas emblemáticas contra o arbítrio e o autoritarismo do Es$\operatorname{tado}^{7}$, e o resultado disso foi justamente a garantia de direitos e deveres que lhe permitem o convívio social em qualquer local, através do fenômeno da constitucionalização.

O convívio social tem ligação íntima com a Fraternidade em razão do Cristianismo, inserido no contexto da Sociedade familiar, e seus ensinamentos no sentido do assistencialismo, da caridade, da ajuda mútua e da compaixão. Anteriormente a isso, a philia Aristotélica ${ }^{8}$ já ensaiava um conceito de Fraternidade, diferenciando-a da amizade, que seria direcionada a uma pessoa específica, enquanto a Fraternidade não teria um determinado número de pessoas. Disseminou-se a categoria como valor,

4 “[...] Técnica de investigação em livros, repertórios jurisprudenciais e coletâneas legais." (PASOLD, 2011, p. 207).

${ }^{5}$ Nas palavras de Pasold (2011, p. 25, grifos do autor): “[...] palavra ou expressão estratégica à elaboração e/ou expressão de uma idéia".

${ }^{6}$ Reitera-se conforme Pasold (2011, p. 37, grifos do autor): “[...] uma definição para uma palavra ou expressão, com o desejo de que tal definição seja aceita para os efeitos das ideias que expomos [...]".

7 As deficiências da sociedade política medieval determinaram as características fundamentais do Estado como instituições político-jurídicas modernas, quais sejam: o território e o povo como elementos materiais; o governo, o poder, a autoridade ou soberano como elementos formais; e a finalidade como elemento substancial. Fonte: Dicionário de filosofia política (BARRETO; CULLETON, 2010, p. 183).

${ }^{8} \mathrm{O}$ conceito aristotélico de amizade é bastante amplo, uma vez que abarca a utilidade, o prazer, o bem e a amizade entre os desiguais. Em todos os tipos de amizade por ele propostos fica clara a exigência da reciprocidade, pois sem ela não será possível falar em amizade. No entanto, para o trabalho que está sendo desenvolvido o mais importante é a amizade como qualidade política. O homem é um ser político e viver em comunidade o torna assim. Daí que a amizade como qualidade política deve ser vista como uma forma a possibilitar novos sujeitos sociais e novos modos de existir e de conviver (ARISTÓTELES, 1999, p. 27). 
no eixo cristão, "[...] mas foram os iluministas que fundamentaram a trilogia na cultura pagã pré-cristã, devido à intensa batalha contra a Igreja e seus desmandes." (BAGGIO, 2008, p. 40). Em 1789, com a Declaração dos Direitos do Homem e do Cidadão, como consequência da Revolução Francesa, a Fraternidade ficou evidenciada, ao lado dos ideais de liberdade e de igualdade, que ultrapassaram as barreiras da harmonia social e do Cristianismo para constituírem elementos de uma Sociedade política, capaz de interferir na forma de governo, bem como integrar textos constitucionais.

Entretanto, no tripé da revolução: "liberdade, igualdade e fraternidade", em que pese o fato da fraternidade aparecer em primeiro plano, juntamente e ao lado da igualdade e da liberdade, "[...] a fraternidade não ocupou papel importante na cultura política do Ocidente". (SAVAGNONE, 2009, p. 195). Isso aconteceu porque igualdade e liberdade foram aceitas, do outro lado do oceano, de maneira muito rápida, como categorias jurídicas e políticas a serem incorporadas nas Constituições.

Facilmente, liberdade e igualdade foram inseridas no contexto jurídico americano, em detrimento da Fraternidade que ficou deslocada em virtude do teor cristão que lhe era característico. Assim, o enfoque dado à Fraternidade era no sentido da educação, do assistencialismo e também outros elementos, mas não adquiriu status jurídico nem político, permanecendo como uma ideologia erguida na bandeira da Revolução Francesa como motivação religiosa, apenas.

Em 1948, a Fraternidade passou a ser elemento chave na modernidade com a universalização do princípio. Logo após, com o fenômeno da constitucionalização, o princípio da Fraternidade passou a ser observado na ordem jurídica interna dos países. Assim, se a regra constitucional fosse descumprida, haveria claramente uma afronta ao Estado Democrático de Direito. É tão relevante a mencionada data, sob o ângulo internacional, porque a Fraternidade adquiriu um novo status em um novo momento histórico, pós-guerra. Logo, a presença da Fraternidade, em 1948, na Declaração Universal dos Direitos do Homem, é bastante forte, quando refere-se a obrigação que todas as pessoas têm de "[...] agir em relação umas às outras com espírito de fraternidade [...]” (BUONOMO, 2009, p. 
169) e de muitas Constituições, como no caso da brasileira atual, que a invoca já no seu Preâmbulo ações nesse sentido.

É importante mencionar que não se pode deixar de considerar a Fraternidade como princípio que possui dimensões que vão muito além da inserida no preâmbulo da Constituição. $\mathrm{O}$ resgate feito até aqui a respeito da fraternidade permite compreender porque comumente esta é associada, segundo o senso comum, a perspectivas ligadas à filosofia e à religião ${ }^{9}$, mas raramente percebida como categoria estatal ${ }^{10}$ ou jurídica, mesmo após sua recepção pelas constituições.

Importa ressaltar a ligação existente entre Princípio da Fraternidade e Direito, no passado, no presente e no futuro: no passado, o desvelo da cumplicidade vivida pelas misérias à época das Revoluções; no presente, como categoria política ${ }^{11}$ e jurídica por meio do fenômeno da constitucionalização; e, no futuro, como objetivo a ser esclarecido e vivenciado em prol do resgate do vínculo antropológico comum e da superação das crises existentes na sociedade do século XXI. Logo, Direito e Fraternidade possuem um caráter de complementaridade que atravessa séculos e que, possivelmente, se perpetuará no tempo como forma de realização da vida em comunidade e da harmonização social. É preciso, cada vez mais,

\footnotetext{
${ }^{9}$ A religião, comumente, lembra-se da bondade e da compaixão para com o próximo.

${ }^{10}$ Para Cunha (2013, p. 300): "Ora, a Fraternidade, ideia muito subtil, precisa de, com o maior dos cuidados, passar para a ribalta das preocupações futuras da ágora. E a República com novo fôlego deverá fazer disso uma (se não mesmo a principal) bandeira. Porque a Fraternidade, e só ela, é capaz de arbitrar e superar mesmo os conflitos entre a Liberdade e Igualdade, que dominaram ('Liberalismo' vs. 'Socialismo') o debate no século passado". 11 "A fraternidade é o cimento ou a amálgama de uma comunidade política - local, nacional e/ou global - que se observa como confiança generalizada. A fraternidade política fundamenta-se num consenso político que inclui dois componente individuais. Primeiro, a existência de procedimentos democráticos legitimados de participação, representação e tomada de decisões políticas, os quais também têm reconhecimento constitucional e que, em geral, favorecem a inclusão política. Segundo, a existência de uma atitude de empatia, preocupação ou solidariedade entre cidadãos, atitude que se expressa no reconhecimento constitucional de direitos sociais e em maiores graus de equidade social." (MARDONES, 2014, p. 44).
} 
insistir num Direito Fraterno Humanista ${ }^{12}$. Nesse sentido é que Marco Aquini (2008, p. 138-139) afirma que a Fraternidade é um valor jurídico fundamental, pois

A fraternidade compromete o homem a agir de forma que não haja cisão entre os seus direitos e os seus deveres, capacitando-o a promover soluções de efetivação de Direitos Fundamentais de forma que, não, necessariamente, dependam, todas, da ação da autoridade pública, seja ela local, nacional ou internacional.

Em que pese o fato de a Fraternidade estar sedimentada como categoria jurídica, amplamente aceita no mundo moderno, é preciso que práticas fraternas sejam socializadas no plano da vida, sob pena de se tornar, novamente, um princípio esquecido. É preciso retomar as condições de Fraternidade, que há séculos está inserida no corpo social, a fim de viabilizar a cooperação mútua entre as pessoas, em momento de crise em que as posturas exclusivamente egoístas imperam de maneira cada vez mais presente. Afirmam-se, dessa forma, o caráter político e jurídico da Fraternidade.

De uma maneira ampla, pode-se afirmar que a qualidade de vida da Humanidade não proporciona espaços para o reconhecimento do Outro. Esse cenário ocorre devido às posturas egoístas, ao consumo de drogas lícitas e ilícitas, à criminalidade, às altas taxas de suicídio, à solidão, à incomunicabilidade, à destruição da identidade humana, à perda de valores, à dissolução de instituições como família, e tantos outros fatores. Sob esta perspectiva, não é exagero dizer que a forma como se vive hoje é insustentável e a Fraternidade pode ser uma alternativa para estas questões. Nessa linha de pensamento:

A Fraternidade é o ponto de unidade a que se chega pela conciliação possível entre os extremos da Liberdade, de um lado, e, de

\footnotetext{
12 "Cada vez mais pensamos que não bastará falar em Direito Fraterno, designação que se arrisca a um pseudo-unanimismo de tintura benfazeja, embora sem rigor. Do Direito Fraterno que tem de tratar-se é de uma concretização jurídica do valor da Fraternidade, e esse é um valor com timbre profundamente humanista. Arriscaríamos, de momento, pois, a sugestão [...] da designação do Direito Fraterno Humanista [...]". (CUNHA, 2013, p. 301).
} 
outro, da Igualdade. A comprovação de que, também nos domínios do Direito e da Política, a virtude está sempre no meio (medius in virtus). Com a plena compreensão, todavia, de que não se chega à unidade sem antes passar pelas dualidades. Este, o fascínio, o mistério, o milagre da vida. (BRITTO, 2007, p. 98)

Mesmo sendo uma herança do cristianismo, a Fraternidade permanece sendo um princípio norteador das relações humanas, pois coloca o sujeito que se orienta a partir da Fraternidade como um membro do corpo social, potencialmente capaz de promover a igualdade e o bem-estar dos cidadãos por meio de um olhar horizontal e que promova a alteridade e não a discriminação. Ademais, no caminho rumo ao futuro, "A fraternidade é uma condição humana, ao mesmo tempo dada - e por isso, constitui um ponto de partida - mas também a ser conquistada, com o compromisso e colaboração de todos." (BAGGIO, 2008, p. 54).

Atualmente, vive-se o ideal da Fraternidade como o ideal da "[...] participação democrática, ou seja, da conexão da ideia de fraternidade com a de cidadania." (BAGGIO, 2009, p. 85). Assim, a Fraternidade encontra-se inserida no contexto social, como categoria jurídica, religiosa, política e social, consolidando a igualdade e a liberdade a partir da responsabilidade entre as pessoas e a formação de suas próprias identidades.

A igualdade e a liberdade ${ }^{13}$ tornam-se vazias sem a orientação da Fraternidade, que é uma condição humana, capaz de fomentar a comunhão universal e fortalecer o vínculo antropológico comum. O vínculo antropológico comum a todos os seres humanos deve ser resgatado porque "Ninguém pode se conhecer totalmente por si mesmo. São os outros, sempre, que completam a visão que nós - como indivíduos e como povos - temos de nós mesmos.” (BAGGIO, 2008, p. 54). Por esse motivo,

13 “"...] Na verdade, as democracias deram alguma eficácia aos princípios da liberdade e da igualdade, mas é evidente que todos esses princípios estão muito longe de sua plena realização. Aliás, a partir da década de 1960, que assistiu à agudização da contestação interna dos sistemas democráticos ocidentais, fortaleceu-se a corrente interpretativa marcada por uma grande desconfiança acerca da dimensão universal dos princípios democráticos, marcada pelo seu 'enfraquecimento', a ponto de duvidar - [...] - da sua aplicabilidade fora dos pequenos agrupamentos, nas vastas sociedades políticas contemporâneas." (BAGGIO, 2008, p. 14). 
verifica-se a importância da Fraternidade como uma categoria jurídica. A partir da previsão constitucional, essa expressão deve ser observada pelo Estado e pelos indivíduos, já que a efetivação de direitos, princípios e valores constitucionais devem ser realizados por todos na vida cotidiana.

É necessário estimular, mais e mais, a existência de um Direito Fraterno $^{14}$, o qual reconheça a humanidade como esse espaço de autorresponsabilização, de reconhecimento das fragilidades comuns, de viabilidade concreta dos Direitos Humanos sem que haja a identificação negativa do Outro como meu "inimigo", seja pela sua "cor", religião, nacionalidade, status político ou econômico ${ }^{15}$. Por esse motivo, Resta (2004, p. 15) destaca que insistir "[...] sobre essas outras visões dos 'códigos fraternos' não é indulgência no sentido de uma ingenuidade destinada a sucumbir na luta ímpar contra o realismo: é somente uma tentativa de valorizar possibilidades diferentes".

A fraternidade, descrita como categoria jurídica, ainda se trata de uma semente que necessita ser cultivada no jardim do tempo. Relevante o debate do tema para que possa ser refletido e inserido com a importância que detém para que haja mais convivência entre os diferentes povos. Essa possibilidade requer a própria adaptação do Direito pelos significados históricos de relações humanas mais fraternas. Ambas necessitam estar interligadas para que seres humanos e o próprio Estado passem a ser sujeitos de direito responsáveis pela realização de uma sociedade mais justa. Fraternidade é o ânimo que põe em movimento a Solidariedade, po-

\footnotetext{
14 "[...] o direito fraterno é um direito jurado em conjunto por irmãos, homens e mulheres, com um pacto em que se 'decide compartilhar' regras mínimas de convivência. Então, é convencional, com um olhar voltado para o futuro. O seu oposto é o 'direito paterno' que é direito imposto pelo 'pai senhor da guerra' sobre o qual se 'deve' somente jurar (iusiurandum). A coniuratio dos irmãos não é contra o pai, ou contra um soberano, um tirano, um inimigo, mas é para a convivência compartilhada, livre de soberania e da inimizade. Esse é um juramento conjunto, mas não é o produto de uma conjura." (RESTA, 2004, p. 133). Grifos originais da obra estudada.

15 "[... É notório que a identificação do 'inimigo' está sempre voltada à manutenção dos confins territoriais e identitários. Por isso entendo fundamental o debate dos anos 30, espantosamente atual, entre Freud e Einstein, onde os temas da guerra e da paz se cruzam com a 'força do direito', mas, sobretudo, com a questão acerca do significado do que seja o amigo da humanidade (RESTA, 2004, p. 14). Grifos originais da obra estudada.
} 
rém não são expressões sinônimas ${ }^{16}$. Sob semelhante argumento, Justiça é o horizonte de humanização do Direito, especialmente no seu significado normativo.

A fraternidade, portanto, busca a perpetuação da paz. A partir desse princípio, outros direitos humanos podem dialogar, como a liberdade e a igualdade, por exemplo. A partir da fraternidade o ser humano pode perceber as fragilidades do outro e auxiliar para o alcance dos seus anseios. A fraternidade como inspiração de conduta, portanto, desvincula o ser humano de uma visão individualista para pensar no outro, com sensibilidade, como ser merecedor das mesmas oportunidades.

\section{O Direito como Meio Potencializador da Fraternidade}

As revoluções ocorridas demonstram sempre esse anseio humano por progredir e obter melhores condições de vida. Os ideais da Revolução Francesa demonstraram claramente este objetivo. Muitas condições de violações a direitos dos seres humanos durante estes períodos de instabilidade fez com que o Direito obtivesse uma posição importante na história da humanidade, já que é um meio de regulação social. Todavia, como um fenômeno de regulação social, deve responder aos anseios humanos por uma maior segurança jurídica sobre determinadas situações. Cada vez mais o Direito se insere em todos os campos da sociedade.

Nesta etapa do estudo, objetiva-se estruturar a ideia da Fraternidade como uma categoria jurídica, de modo que a Fraternidade tenha o respaldo do Direito. O que se propõe é que o Direito pode ser uma garantia da continuidade da Fraternidade ${ }^{17}$. Diferentemente de outros valores, a Fra-

16 "Solidariedade nem sempre constitui situação de paridade e reciprocidade. Por exemplo: pode-se ser solidário a uma determinada causa e empreender ações para cumpri-la, mas não significa que eu reconheço as pessoas envolvidas, inclusive aquele no qual viabilizou a iniciativa solidária, como iguais, ou seja, pertencentes ao vínculo antropológico comum, à família humana na qual destaca o Preâmbulo da Declaração Universal dos Direitos Humanos." (AQUINI, 2008, p. 138).

17 "A constituição do âmbito fraterno jamais ocorre numa relação (de subordinação) entre 'fortes' e 'fracos'. A Fraternidade demonstrou, no decorrer do tempo, que a sua capacidade de reconhecimento e integração entre os seres humanos se revela pela sua fragilidade, 
ternidade ainda não encontrou o espaço adequado nos documentos mais importantes de cada Estado. Exemplo disso é que os ideais da Revolução Francesa "Liberdade e Igualdade" estão solidificadas em constituições de países democráticos. Na Modernidade, essa postura exige uma adaptação do Direito, pois é este o meio potencializador de segurança e dos objetivos de uma sociedade livre e justa. Na Constituição brasileira os ideais da Revolução Francesa estão presentes no preâmbulo constitucional. No artigo $3^{\circ}$ da Constituição, que enumera os objetivos fundamentais da República, os direitos de Liberdade e Igualdade são amplamente protegidos, a Fraternidade, no entanto, pode ser subetentendida por meio do reconhecimento da Solidariedade como um dos objetivos do Estado.

Como se vê, a Constituição demonstra seu objetivo de uma sociedade fraterna e solidária que pode acontecer em um Estado Democrático de Direito, contudo, expressamente não prevê a Fraternidade como um direito ou um dever pelo qual as pessoas possam demandar:

Em suma, o preâmbulo diz que há, no Brasil, um Estado Democrático de Direito, em que o exercício dos direitos sociais e individuais, a liberdade, a segurança, o bem-estar, o desenvolvimento, a igualdade e a justiça, ou seja, os valores supremos de uma sociedade fraterna, estão assegurados. [...] o texto constitucional não cria uma sociedade fraterna, mas reconhece a fraternidade como uma dimensão ética e valorativa a ser buscada no solo fértil de um Estado de Direito. (VIEIRA, CAMARGO, 2013, p. 124)

A Constituição Federal, portanto, reconhece de forma peculiar ${ }^{18}$ a fraternidade. Diante do que fora dito é possível perceber que o texto cons-

sua finitude, enfim, sua(s) incompletude(s). O Direito, a partir da categoria em estudo, se revela, transforma e protege aqueles nos quais pertencem ao vínculo antropológico comum inserido na tríade indivíduo-sociedade-espécie. [...] Fraternidade e Solidariedade são categorias políticas e jurídicas vitais para se reforçar a Responsabilidade entre as pessoas por comungarem um vínculo antropológico comum que ultrapassa identidades nacionais as quais se caracterizam pela postura de egoísmo em detrimento ao altruísmo. (AQUINO, 2014, p. 273-275).

${ }^{18} \mathrm{~A}$ forma peculiar pela qual se reconhece a fraternidade deriva da sua relação com a solidariedade, que se apresenta com força normativa na medida em que esta é um dos objetivos da República brasileira constantes no artigo terceiro da Constituição de 1988. E 
titucional brasileiro prevê o princípio da solidariedade em seu artigo $3^{\circ} \mathrm{e}$ ideais de uma sociedade fraterna em seu preâmbulo. Isso demonstra que, embora não seja essencialmente claro, a Constituição faz esta conexão entre Direito e Fraternidade. Com isso, a fraternidade deve ser um princípio a orientar a interpretação constitucional e a conduta estatal e humana.

A Fraternidade demanda do Estado e das pessoas uma posição para se perpetuar no tempo e espaço. Não se deve apenas esperar do Estado a construção de uma sociedade fraterna. Essa condição deve partir das ações dos seres humanos. Deveres individuais potencializam uma sociedade fraterna, que constrói a concepção de nós, do eu junto com o outro e não do eu $e$ os outros.

O Direito não molda apenas a ação do Estado, como também a ação dos indivíduos no sentido da construção de uma sociedade solidária. (VIEIRA; CAMARGO, 2013, p. 127). Nessa linha de pensamento, a Fraternidade aproxima o próprio Direito da Moral, pois demanda comportamentos que priorizam determinados valores para a construção de uma vida pacífica em sociedade.

A Fraternidade estimula ações morais de zelo junto ao Outro que observa no Direito um meio de se institucionalizar e garantir a viabilidade da Justiça. O Direito pode, sim, ser um meio de potencializar atitudes fraternas e uma sociedade que prime por esses princípios, pois:

O Direito aponta que nas relações entre o Estado e indivíduos, entre indivíduos e a sociedade e entre indivíduos no âmbito de suas relações privadas deve ser buscada uma sociedade fraterna. Afinal, compartilhamos da mesmíssima condição humana, ou seja, um

isso acontece porque a fraternidade é a orientação valorativa ao princípio da solidariedade. Para complementar esta ideia refere-se as palavras de Aquino (2014, p. 273): "Por esse motivo, quando a Norma Jurídica define as formas de solidariedade vertical, percebese a manifestação da Fraternidade sob sua vertente legal, como se depreende da leitura do $\operatorname{artigo} 3^{\circ}$ da Constituição Federal. Entretanto, esse vínculo do "forte" ao "fraco" esvazia os sentimentos responsáveis provocados pela identificação antropológica comum. Não existem dúvidas de que é necessário positivar garantias as quais viabilizem formas de Solidariedade, porém o estímulo ao reconhecimento do Outro e o resgate da Responsabilidade de todos com todos é uma ação histórica espontânea". 
complexo reservatório onde potencialidades e fraquezas coexistem. Se pudermos estar no mundo (jurídico) com a consciência voltada para um nós no lugar de um eu e os outros, talvez o sentimento de descrença no Direito se dissipe e possamos contribuir para uma sociedade mais generosa e justa. (VIEIRA, CAMARGO, 2013, p. 129)

Embora uma sociedade fraterna seja um dos anseios da Constituição Federal brasileira, ainda se carece em reconhecer sua normatividade. A Fraternidade possui um caráter de validade e vigência, mas, de certa forma, não tem sido eficaz. Quando o preâmbulo constitucional refere princípios a partir dos quais deve ser interpretada a Constituição e dentre estes se encontra a sociedade fraterna, significa afirmar que sua inserção na Constituição passou pelos trâmites legais, na medida em que constante do texto constitucional. Se é assim, a fraternidade é o princípio que se estende à solidariedade, objetivo da República Federativa do Brasil. Logo, é válido e vigente, mas não eficaz. A imposição de uma obrigação constitucional - ainda que fraterna - nem sempre acolhe aqueles postos à margem dos limites (semânticos) da lei ${ }^{19}$.

A questão da normatividade da Constituição ${ }^{20}$ não se refere apenas à questão da Fraternidade. Trata-se de um assunto que deve ser colocado em debate, tendo em vista a importância desse tema. Faller (2013, p. 156) alerta para este fato quando explica:

Os debates acerca da baixa normatividade constitucional no Brasil são complexos e não há como ser diferente. Quando se trata de Direito Constitucional, a discussão deve ser alargada, pois se toca

\footnotetext{
19 "[...] o direito fraterno é inclusivo, no sentido de que escolhe direitos fundamentais e define o acesso universalmente compartilhado a bens 'inclusivos'. Bens e direitos fundamentais são inclusivos, quando um indivíduo não pode gozar deles, se, no mesmo momento não gozam deles todos os outros. $\mathrm{O}$ ar, a vida, o patrimônio genético só podem ser inclusivos, podem sê-los menos as propriedades, quando não são igualmente distribuídas." (RESTA, 2004, p. 135, grifos do autor).

${ }^{20}$ A Constituição não configura apenas a expressão de um ser, mas também de um dever ser. Graças à pretensão de eficácia, a Constituição procura imprimir ordem e conformação à realidade política e social. Ela não é apenas determinada pela realidade social, mas também determinante em relação a ela. Com isso a Constituição adquire força normativa conforme realiza sua pretensão de eficácia (HESSE, 1991, p. 15-16).
} 
na política, na teoria do Estado, na vida de uma sociedade que se constitui ao redor deste pacto fundamental. É necessário dialogar com outras áreas do conhecimento e compreender o Direito a partir de sua dinâmica social.

Sob esse argumento, o Direito, hoje, padece com essa dificuldade de transitar, por meio do diálogo, entre outros saberes humanos. Muitas normas jurídicas são válidas, vigentes, mas carecedoras de eficácia, tal e qual a questão da Fraternidade. Por esse motivo, a exigência de nosso tempo é de refletir como essas questões possibilitam uma convivência mais digna para todos no momento em que se enxerga, com maior nitidez, o vínculo antropológico comum a partir da Fraternidade.

A Fraternidade poderia, desde já, ser entendida como uma categoria jurídica, já que, mesmo indiretamente, é prevista pela Constituição Federal. No entanto, ao carecer de eficácia, suscita mais espaços de debate sobre a sua importância histórica, o seu projeto de integração humana, bem como a postura pedagógica estabelecida pela Constituição no sentido de rememorar a sua necessidade para que haja unidade humana a partir da pluralidade de diferenças que habitam o cotidiano das relações.

A Fraternidade, se encarada como um princípio jurídico, pode auxiliar neste debate ao demonstrar a necessidade do comprometimento de todos para que ocorra a sociedade objetivada pelo preâmbulo constitucional. Ao fomentar uma sociedade fraterna, se está a fazer com que todos atuem para a construção permanente do Estado Democrático de Direito.

A Constituição Brasileira, em seu preâmbulo delimita objetivos que serão perseguidos pelo texto constitucional e que compromete o Estado e seus cidadãos na busca por sua realização. "Veja: não se trata de nada mais, mas tão somente da realização de promessas proclamadas historicamente e das quais dependem a maturação de um efetivo regime democrático no Brasil." (FALLER, 2013, p. 157).

Diante desse cenário, a Fraternidade pode ser encarada como uma categoria jurídica, assim como os demais ideais da Revolução Francesa. No entanto, a Fraternidade encontra limites em seu enquadramento como norma constitucional, haja vista que sofre uma limitação em sua eficá- 
cia, sendo difícil sua exigibilidade, já que a Constituição não assegura em qualquer norma constitucional a fraternidade como um direito, fundamento ou objetivo estatal.

A fraternidade, nesse sentido, é um elemento jurídico capaz de amenizar as relações humanas, tornando-as mais leves. Essa reflexão da fraternidade como um princípio a orientar as relações, reconhecido mesmo que precariamente pelo Direito, demanda deste uma postura diferente. A seletividade do direito penal, medida inconcebível ainda nos dias atuais, demonstra a necessidade do reconhecimento da fraternidade como um princípio de ordem jurídica a orientar os seres humanos a perceberem no outro, independentemente das diferenças concretas entre eles, um ser humano merecedor do mesmo respeito e consideração. Todos os seres humanos são livres e iguais, mediante os próprios preceitos constitucionais, e o olhar constitucional fraterno ao outro deve impedir que seres humanos sejam selecionados pela sociedade, bem como pelo sistema, como pessoas potencialmente infratoras a partir de suas diferenças físicas e sociais. É o que o próximo item do estudo se propõe a observar.

\section{Seletividade do Direito Penal Segundo à Criminologia Crítica e a Fraternidade: uma aproximação necessária}

O movimento chamado Criminologia Crítica proporciona uma melhor visualização dos fenômenos criminais a partir dos fundamentos da Criminologia Clássica. Analisa-se, por meio de perspectivas históricas e do discurso marxista, a eleição de indivíduos como potencialmente criminosos, os processos de etiquetamento e rotulação, bem como a interferência dos grupos de poder na sociedade. Além disso, demonstra-se a existência de uma seletividade discriminatória do sistema penal (GARCÍA-PABLOS DE MOLINA; GOMES, 2000, p. 321).

Uma nova forma de análise do fenômeno criminológico passou a vigorar neste contexto, especialmente com o surgimento do "labelling approach", como um significado de "desviação" e uma qualidade atribuída por processos de interação altamente seletivos e discriminatórios, onde o conceito de criminoso é estabelecido por grupos distintos que instituem 
os critérios utilizados pelo sistema penal no exercício do controle social para definir o desviado de acordo com essas características (BECKER, 2008, p. 120).

Por certo, o bem jurídico protegido pelo Direito Penal acaba desvirtuando-se, à medida que os atos condenáveis passam a ser nem sempre aqueles mais danosos. A eleição do perfil do criminoso, em um processo de criminalização instituído na sociedade, dá azo à supressão de direitos, liberdades e garantias constitucionais. Logo, a justiça criminal e o sistema penal são seletivos e isso ocorre como decorrência de frequentes processos seletivos discriminatórios.

A Criminologia Crítica propõe, neste contexto de crise do sistema penal e dos excessos cometidos, uma nova forma de interpretação do crime. A ruptura na reflexão criminológica liberal é evidente, já que os pensamentos criminológicos clássicos não questionam os processos de criminalização nem a eleição do perfil ou da conduta do criminoso. Nos dias de hoje, os processos de criminalização estão cada vez mais presentes. O Direito Penal deslegitima-se, à medida que está à serviço de uma parcela social, que detêm o poder político-dominante. O Direito Penal acentua os processos referidos, à medida que não funciona mais como última ratio. Esse é um recurso jurídico utilizado pelas “[...] parcelas sociais detentoras de poder para assegurar a sobrevivência do sistema capitalista, que é posteriormente ameaçado por suas próprias contradições" (QUINNEY, 1980, p. 245-246).

Assim, o controle penal ocorre de forma a segregar, sendo que: os bens jurídicos precisam ser revisitados e reconsiderados, há diferenças de tratamentos ainda que a lei considere a condição de igualdade, e a seleção do perfil de criminoso ocorre de um grupo para outro, em razão de processos de dominação que guardam estreita relação com o capital. Nessa senda, cabe questionar até mesmo o que o Direito Penal busca, atualmente, legitimar, já que, segundo Gauer (1999, p. 18) “[...] a violência dos poderosos recebe uma crítica que se esgota no discurso inócuo. A violência dos fracos, por outro lado, é punida concretamente [...]". No mesmo sentido, menciona Baratta (2002, p. 160-161) que: 
[...] o salto qualitativo que separa a nova da velha criminologia consiste, portanto, principalmente, na superação do paradigma etiológico, que era o paradigma fundamental de uma ciência entendida, naturalisticamente, como teoria das causas da criminalidade.

Na perspectiva da Criminologia Crítica, a criminalidade não é mais uma qualidade ontológica de determinados comportamentos e de determinados indivíduos, mas se revela, principalmente, como status atribuído a determinados indivíduos, mediante uma dupla seleção: em primeiro lugar, a seleção dos bens protegidos penalmente, dos comportamentos ofensivos destes bens, descritos nos tipos penais; em segundo lugar, a seleção dos indivíduos estigmatizados entre todos os indivíduos que realizam infrações a normas penalmente sancionadas ${ }^{21}$.

Não é por outra razão que na obra de Rusche e Kirchheimer ${ }^{22}$, os autores já haviam apontado a relação entre a estrutura social e a punição trazendo mestral exemplo de seletividade ao fazerem a constatação de que no século XIV, quando aproximadamente um terço da população da Europa foi dizimada pela doença conhecida como "Peste Negra", as normas penais eram muito tímidas e interferiam pouco na vida em sociedade, posto que a escassez da mão de obra, exigia do Estado uma postura libertária. A partir do contorno da doença com programas governamentais de aumento da natalidade, quatro séculos mais tarde, com a "reposição" da população e com o, agora, excesso de mão de obra, novamente surgem delitos como vadiagem, furto, entre outros.

${ }^{21}$ Para Wacquant (2007, p. 223): "Os autores de infrações de 'colarinho branco' são, a princípio, muito menos suscetíveis de serem detectados, perseguidos e condenados que os delinquentes de rua. Depois, quando são condenados, as sanções a eles impostas excluem, na maior parte dos casos, a privação da liberdade. Enfim, quando, excepcionalmente, são presos, as penas que têm de pagar são bem mais reduzidas. [...] Assim, a mesma década que vê os pequenos traficantes e os consumidores de drogas dos bairros pobres serem jogados nas prisões aos milhares, por estadas que são marcadas em anos, e os sem-teto abarrotarem as casas de detenção pelo único motivo de pedirem esmolas ou importunarem os comerciantes da Main Street, é também aquela em que a 'malversação em quadrilha organizada', crime típico do capitalismo dominado pelo capital financeiro, se generaliza e em que a fraude atinge seu ápice na Wall Street, numa impunidade quase total".

22 The New Criminology: For a Social Theory of Deviance. 
Contudo, a referida obra “[...] não exaure o tema da marginalização criminal, porque o mercado de trabalho, no sistema capitalista de produção, vai para além da perspectiva econômica, alcançando uma dimensão política também.” (BARATTA, 2002, p. 189). Os contornos do tema estão presentes na atualidade e o debate sobre Seletividade do Sistema Penal Brasileiro é um debate pertinente, tendo em vista a atual dinâmica social do país, resultado de uma construção sociocultural bastante diversificada. Observa-se uma influência da linguagem, da cultura, da mídia e da imposição de valores sociais nos discursos de poder, que estão, à todo tempo, legitimando um processo de eleição - ainda que inconsciente - de condutas criminosas e do perfil do criminoso.

Os processos de criminalização são objetos de estudo da Criminologia Crítica que desde 1960 busca respostas aos questionamentos oriundos da relação existente entre criminalidade e capitalismo. Nesse sentido, a própria ciência penal está sendo colocada à prova. Os grupos privilegiados, ou ainda, as forças sociais mais expressivas determinam os destinatários da norma penal, legitimando processos históricos de dominação e agravando as disfunções sociais já existentes. A repressão institucional é sustentada pelo sentimento de raiva, medo ou vingança de quem domina, ao passo que a punição é direcionada àquele que já é vitimado pela segregação ou exclusão social. Os impulsos sociais vão ao encontro de uma violência que seleciona e controla, aliada a um Sistema Penal que se mostra instrumento de opressão e dominação por excelência.

A institucionalização do controle e a legitimação dos discursos de poder demonstram a falta de sintonia entre Direito Penal e suas funções. Na Criminologia Crítica, o Direito Penal não é considerado somente como sistema estático de normas jurídicas, mas como sistema dinâmico de funções, no qual se podem distinguir três mecanismos analisáveis separadamente: o mecanismo da produção de normas, o mecanismo da aplicação das normas, e o mecanismo de cumprimento da pena. Nessa linha de pensamento, o poder e a violência estão institucionalizados e são determinantes na análise da violação de direitos e garantias fundamentais de certos indivíduos. Os rígidos critérios para a intervenção penal estão relativizados, pois se direcionam a perfis predeterminados. 
As consequências desse processo são gravíssimas: as cotas de violência inseridas nas relações sociais estão em crescimento, assim como a população carcerária. Além disso, essa dinâmica sustenta o discurso da relativização de Direitos Humanos, em nome da manutenção da "ordem pública" e da preservação de uma lógica institucional que a própria sociedade corrobora. O Estado de Direito encontra-se esfacelado, diante dos componentes arbitrários que restringem a liberdade e enfraquecem os direitos. Para exemplificar, em relação ao controle realizado pelas agências de polícia, Wacquant (2001, p. 9) destaca:

Essa violência policial inscreve-se em uma tradição nacional multissecular de controle dos miseráveis pela força, tradição oriunda da escravidão e dos conflitos agrários, que se viu fortalecida por décadas de ditadura militar, quando a luta contra a "subversão interna" se disfarçou em repressão aos delinqüentes. Ela apoia-se numa concepção hierárquica e paternalista da cidadania, fundada na oposição cultural entre feras e doutores, os "selvagens" e os "cultos", que tende a assimilar marginais, trabalhadores e criminosos, de modo que a manutenção da ordem de classe e a manutenção da ordem pública se confundam.

O mesmo autor completa afirmando ainda que o Direito Penal, em particular, reflete uma contradição fundamental entre igualdade dos sujeitos de direito e desigualdade substancial dos indivíduos. Zaffaroni e Pierangeli (1999, p. 77) também lecionam nesse sentido e verificam que o sistema penal tem uma função que se esconde por trás do discurso externo, de proteção social indistinta, em um pretenso Direito Penal igualitário. Sob a ótica destes autores, conclui-se que o discurso penal atual e:

[...] o sistema penal é extremamente seletivo no combate ao crime. Desde a elaboração de normas proibitivas de condutas, até a punição judicial de criminosos, há uma perversa seleção de agentes que irão sofrer a efetivação da sanção penal. $\mathrm{O}$ status quo que impera no combate à criminalidade é alarmante. No intuito de manter calma a desinformada sociedade, direciona-se a punição a determinadas condutas (com doses altíssimas de publicidade) e cria-se a idéia de que a criminalidade está controlada. Falsa ilusão simbólica, 
porquanto a mais perversa e destruidora forma de criminalidade, a de cunho econômico, está a proliferar-se, sem que os órgãos estatais previnam e combatam tais formas de delito. A seletividade estrutural do sistema penal - que só pode exercer seu poder regressivo legal em um número insignificante das hipóteses de intervenção planificadas é a mais elementar demonstração da falsidade da legalidade processual proclamada pelo discurso jurídico-penal. Os órgãos executivos têm "espaço legal" para exercer poder repressivo sobre qualquer habitante, mas operam quando e contra quem decidem.

Assim, as características do sistema penal o tornam ilegítimo, face ao tratamento desigual que confere aos membros da sociedade, além de servir como instrumento de controle social seletivo e discriminatório. Diante da falência do sistema, viabilizar alternativas ao sistema é um desafio à sociedade, além de uma necessidade. Não se almeja que o Direito perca sua força ou que a lei, como imperativo social, deixe de cumprir sua função. Mas sim, busca-se, com um olhar crítico-criminológico, uma nova forma de estruturar esta seletividade, segregadora e elitista.

A Fraternidade pode ser uma alternativa neste sentido. Como princípio norteador, é capaz de fomentar a ideia de uma comunidade, onde as pessoas consigam viver em paz. (BAGGIO, 2008, p. 53-54). Por certo, com o conflito instalado, essa ideia parece ser difícil de ser alcançada. Contudo, direitos tão caros ao Direito Penal, como igualdade e a liberdade tornam-se vazios sem a fraternidade. Explica-se: se vivida fraternalmente, a liberdade não se torna vontade do mais forte, assim como a igualdade não degenera em igualitarismo impiedoso (BAGGIO, 2008, p. 53-54).

Sob a mesma linha de pensamento, Morin (2011, p. 43) entende que cabe à arte da política, a missão de alcançar um ideal humano de liberdade, igualdade e Fraternidade, como uma "via", um caminho para a salvação. E salienta que essa nova política deverá obedecer a uma dupla orientação: uma política de humanidade e uma política de civilização. Portanto, para a continuidade da própria Humanidade faz-se necessário resgatar a categoria da Fraternidade, tanto no âmbito religioso que prega que "[...] todos os homens são iguais e livres porque são irmãos [...]" (MORIN, 2011, p. 53), quanto na dimensão política, fazendo com que a 
Humanidade retire as vestes da individualidade e em sua nudez se reinvente, fortalecendo o vínculo antropológico comum, em todas as áreas do Direito, e em especial, no Direito Penal.

Em um sistema falido e com o discurso de ódio que se inculca a todo tempo na sociedade, destinado a rotular o perfil do criminoso, mostra-se importante e necessário resgatar valores que restaram esquecidos na trajetória humana. Dentre eles, revestido de um caráter constitucional, que ainda precisa ser aprimorado, está a Fraternidade. Esta pode ser um meio de potencializar a humanidade presente em cada um, trazendo à reflexão e ao debate essa outra necessidade de transformação: que se trata do olhar seletivo em relação aqueles que são os escolhidos, a partir de suas condições físicas e sociais, a serem condenados por um sistema penal deficitário e por uma sociedade segregadora.

\section{Conclusão}

A Fraternidade, por muito tempo, restou esquecida, encoberta por valores que pareciam mais essenciais, úteis e imediatos, como a Liberdade a Igualdade. Contudo, na sociedade contemporânea, cada vez mais as relações humanas estão pautadas pelas exclusões sociais, pelas misérias, pela eliminação do Outro. Os laços de Fraternidade se enfraquecem. Os sujeitos encontram-se cada vez mais isolados e as posturas egoístas se ampliam. É necessário resgatar certos valores para se enfrentar as crises sociais, jurídicas, políticas, culturais - contemporâneas.

A partir da experimentação e vivência da Fraternidade, a Humanidade criará vínculos repletos de conhecimentos e aprendizagens compartilhadas, nos quais será possível se modificar e potencializar suas habilidades, como uma vida mais humana e sustentável.

O Direito, como um fenômeno social que acompanha essas transformações, deve estar atento a esse processo. Vive-se um momento de encobrimento da Alteridade, mas, por meio da Fraternidade, desfaz-se o rígido gelo pelo calor do acolhimento humano. Já se sabe da importância de um mundo mais fraterno. No entanto, ao estruturar a categoria Fraternidade como um princípio a ser respeitado pelos seres humanos e pelo 
Estado, estar-se-ia dando um passo ímpar na direção de relações sociais e políticas mais justas.

Há necessidade de uma conscientização a respeito da importância da Fraternidade para o mundo da vida. $\mathrm{O}$ valor da Fraternidade é um caminho a ser revisitado e (re) experimentado, propiciando espaço a experiências genuinamente humanas, especialmente quando se trata da crise enfrentada na esfera penal, no tocante à Seletividade do Direito Penal.

Conforme os fundamentos revisitados na segunda parte desta pesquisa, é possível perceber que os processos de criminalização são objeto de estudo da Criminologia Crítica e estão institucionalizados na sociedade de hoje, de forma a legitimar discursos punitivos discriminatórios e seletistas.

Desse modo, mídia, linguagem, cultura e interações sociais (que denotam poderio de uns em face aos outros) interferem diretamente no processo de escolha daqueles que são ou não considerados criminosos, à partir de uma perspectiva de dominação.

Os diplomas legais corroboram esta situação: privilegiam, por um lado, o patrimônio, o lucro daqueles que o detém, e, por outro, promovem a segregação, a eliminação daqueles que não conseguem se adaptar às exigências de "civilidade" pelos parâmetros dos méritos pessoais e da Economia. Evidente que neste panorama, não há como se falar em direitos e garantias fundamentais a todos. O ideal de Fraternidade, aos poucos, se esmaece pela ausência de estar junto com o Outro.

Por certo, o sistema prisional controla aqueles denominados de criminosos por uma camada da população, sendo que os processos desiguais são a regra, mesmo em um Estado Democrático de Direito onde se pressupõe a liberdade e igualdade para todos.

Percebe-se que o movimento surgido com a Criminologia Crítica ainda não está sedimentado e nem possui a pretensão de resolver todos os flagelos da complexa sociedade em que se vive, mas denota uma nova perspectiva de encarar a realidade, por meio de críticas e reflexões que envolvem o sistema jurídico, as desigualdades sociais e o que está à serviço de quem nos processos de criminalização. Do mesmo modo, a Frater- 
nidade, somada à esta questão, como alternativa a um panorama diferente à crise instaurada se mostra um caminho viável a ser trilhado na modificação desse panorama.

\section{Referências}

AQUINI, Marco. Fraternidade e direitos humanos. In. Antônio Maria Baggio (Org.). O princípio esquecido: a fraternidade na reflexão atual das ciências políticas. Tradução de Durval Cordas, Iolanda Gaspar, José Maria de Almeida. Vargem Grande Paulista, (SP): Cidade Nova, 2008.

AQUINO, Sérgio Ricardo Fernandes de. Por uma cidadania sulamericana: fundamentos para sua viabilidade na UNASUL por meio da ética, fraternidade, sustentabilidade e política jurídica. Saabrücken: Novas Edições Acadêmicas, 2014.

ARISTÓTELES. Ética a Nicômacos. Tradução de Mário da Gama Cury. 3. ed. Brasília: UNB, c1985, 1999.

BAGGIO, Antônio Maria. A ideia de fraternidade em duas Revoluções: Paris 1789 e Haiti 1791. In: BAGGIO, Antônio Maria (Org.).

O princípio esquecido/1. Vargem Grande Paulista, (SP): Cidade Nova, 2008. p. 25-56.

BAGGIO, Antônio Maria. A inteligência fraterna. Democracia e participação na era dos fragmentos. In: BAGGIO, Antônio Maria (Org.). O princípio esquecido/2. Vargem Grande Paulista, SP: Cidade Nova, 2009. p. 85-130.

BARATTA, Alessandro. Criminologia crítica e crítica do direito penal: introdução à sociologia do direito penal. 2. ed. Rio de Janeiro: Freitas Bastos, 2002.

BARRETO, Vicente de Paulo; CULLETON, Alfredo (Org.). Dicionário de filosofia política. São Leopoldo: Unisinos, 2010.

BECKER, Howard S. Outsiders: estudos de sociologia do desvio. Rio de Janeiro: Jorge Zahar. 2008. 
BITTAR, Eduardo C. B. O Direito na pós-modernidade (e reflexões frankfurtianas). 2. ed. Rio de Janeiro: Forense Universitária, 2009.

BRITTO, Carlos Ayres. O Humanismo como categoria constitucional. Belo Horizonte: Fórum, 2007.

BUONOMO, Vincenzo. Vínculos relacionais e modelo de fraternidade no direito da Comunidade Internacional. In: BAGGIO, Antônio Maria (Org.). O princípio esquecido/2. Vargem Grande Paulista, SP: Cidade Nova, 2009. p. 151-173.

CUNHA, Paulo Ferreira da. Nova teoria do Estado: Estado, República e Constituição. São Paulo: Malheiros, 2013.

CURY, Munir. Direito e fraternidade na construção da justiça. In: VERONOSE, Josiane Rose Petry; OLIVEIRA, Olga Maria Boschi Aguiar de (Org.). Direitos na pós-modernidade: a fraternidade me questão. Florianópolis: Fundação Boiteux, 2011. p. 325-352.

DIAS, Maria da Graça dos Santos. Sociedade. In: BARRETO, Vicente de Paulo. Dicionário de filosofia política. São Leopoldo, (RS): Editora da UNISINOS, 2010. p. 487-490.

FALLER, Maria Helena Pereira Fonseca. O princípio da fraternidade e o constitucionalismo moderno: uma nova possibilidade de leitura das constituições contemporâneas. In: VERONOSE, Josiane Rose Petry; OLIVEIRA, Olga Maria Boschi Aguiar de (Org.). Direitos na pósmodernidade: a fraternidade me questão. Florianópolis: Fundação Boiteux, 2011. p. 353-382.

GARCÍA-PABLOS DE MOLINA, Antônio; GOMES, Luiz Flávio. Criminologia - introdução a seus fundamentos teóricos: introdução às bases criminológicas da Lei 9.099/95, Lei dos Juizados Especiais Criminais. 3. ed. São Paulo: Revista dos Tribunais, 2000.

GAUER, Ruth Maria Chittó. Alguns aspectos da fenomenologia da violência. In: GAUER, Gabriel José Chittó; GAUER, Ruth Maria Chittó (Org.). A fenomenologia da violência. Curitiba: Juruá, 1999. p. 13-35. HESSE, Konrad. A Força Normativa da Constituição. Tradução de Gilmar Ferreira Mendes. Porto Alegre: Safe, 1991. 
IGHINA, Domingo. "Unidos ou dominados". Sobre uma leitura da fraternidade em função latino-americana. In: BAGGIO, Antonio Maria (Org.). O princípio esquecido/2. Vargem Grande Paulista, (SP): Cidade Nova, 2009. p. 33-42.

LÉVINAS, Emmanuel. Totalidade e infinito. Tradução de José Pinto Ribeiro. Lisboa: Edições 70, 2000.

MARDONES, Rodrigo. Por uma exatidão conceitual da fraternidade política. In: LOPES, Paulo Munir (Org.). A fraternidade em debate: percurso de estudos na América Latina. Vargem Grande Paulista, (SP): Cidade Nova, 2012. p. 19-44.

MORIN, Edgar. La vía para el futuro de la humanidad. Traducción de Núria Petit Fontseré. Barcelona: Paidós, 2011.

PASOLD, Cesar Luiz. Metodologia da pesquisa jurídica: teoria e prática. 12. ed. São Paulo: Conceito Editorial, 2011.

PEZZIMENTI, Rocco. Fraternidade: o porquê de um eclipse. In: BAGGIO, Antonio Maria (Org.). O princípio esquecido/1. Vargem Grande Paulista, SP: Cidade Nova, 2008. p. 57-76.

QUEIROZ, Paulo de Souza. Direito penal: introdução crítica. São Paulo: Saraiva, 2001.

QUINNEY, Richard. O controle do crime na sociedade capitalista: uma filosofia crítica da ordem legal. In: TAYLOR, Ian; WALTON, Paul; YOUNG, Young. (Org.). Criminologia crítica. Tradução Juarez Cirino dos Santos e Sérgio Tancredo. Rio de Janeiro: Graal, 1980. p. 221-249. RESTA, Elígio. Direito fraterno. Tradução de Sandra Regina Martini Vial. Santa Cruz do Sul, (RS): EDUNISC, 2004.

RUSCHE, George; KIRCHHEIMER, Otto. Punição e Estrutura Social. 2. ed. Rio de Janeiro: Editora Revan, 2004.

SAVAGNONE, Giuseppe. Fraternidade e comunicação, com especial referencia à comunicação jornalística. In: BAGGIO, Antonio Maria (Org.). O princípio esquecido/2. Vargem Grande Paulista, (SP): Cidade Nova, 2009. p. 195-248. 
WACQUANT, Loic. As prisões da miséria. Rio de Janeiro: Jorge Zahar, 2001.

. Punir os pobres: a nova gestão da misérias nos Estados Unidos [A onda punitiva]. Tradução de Sérgio Lamarrão. 3. ed. Rio de Janeiro: Revan, 2007.

ZAFFARONI, Eugênio Raul. Em busca das penas perdidas: a perda da legitimidade do sistema penal. Tradução Romano Pedrosa e Amir Lopez da Conceição. 6. ed. Rio de Janeiro: Revan, 2001.

ZAFFARONI, Eugênio Raul; PIERANGELI, José Henrique. Manual de Direito Penal Brasileiro: parte geral. 2. ed. São Paulo: Revista dos Tribunais, 1999.

Sérgio Ricardo Aquino Fernandes é professor de Direito na Faculdade Meridional (RS) e na pós-graduação stricto sensu em Direito do Complexo de Ensino Superior Meridional (RS), doutor e mestre em Ciência Jurídica pela Universidade do Vale do Itajaí (SC) e coordenador do grupo de pesquisa Ética, Cidadania e Sustentabilidade (Faculdade Meridional, RS).

E-mail: sergio.aquino@imed.edu.br.

Endereço profissional: Faculdade Meridional, Rua Senador Pinheiro, n. 304, Vila Rodrigues, Passo Fundo, RS - 99070-220.

Mayara Pellenz é professora no Instituto Blumenauense de Ensino Superior (SC) e na Faculdade Avantis (SC), mestre em Direito pela Faculdade Meridional (RS), especializada em Direito Penal e Processo Penal pela mesma instituição, graduada em Direito pela Universidade de Passo Fundo (RS) e pesquisadora no grupo Ética, Cidadania e Sustentabilidade (Faculdade Meridional, RS).

E-mail:maypellenz@hotmail.com.

Endereço profissional: Faculdade Meridional, grupo de pesquisa "Ética, Cidadania e Sustentabilidade”, Rua Senador Pinheiro, n. 304, Vila Rodrigues, Passo Fundo, RS - 99070-220. 
Ana Cristina Bacega de Bastiani é professora de Direito na Faculdade Meridional (RS), mestre em Direito pela Faculdade Meridional (RS), especializada em Direito Processual Civil pela Faculdade Anhanguera (RS), graduada em Direito pela mesma instituição e pesquisadora no grupo Ética, Cidadania e Sustentabilidade (Faculdade Meridional, RS).

E-mail: cristi.bd@hotmail.com.

Endereço profissional: Faculdade Meridional, grupo de pesquisa “Ética, Cidadania e Sustentabilidade”, Rua Senador Pinheiro, n. 304, Vila Rodrigues, Passo Fundo, RS - 99070-220. 